\title{
CASTAÑO, SERGIO RAÚL (2018). IL POTERE COSTITUENTE TRA MITO E REALTÀ, PREFACIO DE PIETRO GIUSEPPE GRASSO. MILANO. GIUFFRÈ FRANCIS LEFEBVRE
}

\author{
Daniel Alejandro Herrera \\ Profesor Titular de Filosofía del Derecho \\ Director de la Carrera de Derecho \\ Universidad Católica Argentina, Buenos Aires, Argentina \\ Contacto: daniel_herrera@uca.edu.ar
}

Recibido: 2 de agosto de 2021

Aprobado: 3 de agosto de 2021

Para citar este texto:

Herrera, D. A.; Castaño, Sergio Raúl (2018). Il potere costituente tra mito e realtà, Prefacio de Pietro Giuseppe Grasso. Milano. Giuffrè Francis Lefebvre. XIV+135 páginas. ISBN 9788828803607. Prudentia Iuris, N. 92. pp. 25-30 DOI: https://doi.org/10.46553/prudentia.92.2021.pp.25-30 
Sergio Castaño, autor, en los últimos años, de Legalidad y legitimidad en el Estado democrático-constitucional (Marcial Pons, 2015, pról. de Dalmacio Negro), Hermann Heller y el valor de la vida política (Derecho Global, 2018, pról. de Jerónimo Molina Cano), El Estado en el orden internacional (EDUCA, 2019) y Dios y la Ciudad. Estudios de Teología Política (UNSTA, 2020), ofrece en este libro una síntesis complexiva de la realidad del poder constituyente.

La presente obra, que ha tenido dos ediciones castellanas (U. Católica de Cuyo, 2012; Academia de Derecho, U. Santo Tomás, 2016), aparece ahora revisada y aumentada en la Collana "Civiltà del Diritto", de Giuffrè, en traducción de Claudia Razza y Renato Cristin, académicos de la Universidad de Trieste; y con un valioso Prefacio del ilustre constitucionalista P. G. Grasso.

El libro se divide en dos partes bien definidas; la primera se refiere al poder político en general (Capítulo I), y la segunda, referida al poder constituyente en especial, subdividiéndola en dos capítulos, uno sobre la naturaleza de la Constitución (Capítulo II) y el otro sobre el poder constituyente como función del poder político (Capítulo III). A esto se le agregan dos apéndices, uno sobre el mito de la soberanía del pueblo (Capítulo IV) y el otro sobre la objeción contrarrevolucionaria a la realidad del poder constituyente (Capítulo V).

I. Comienza la primera parte con una reflexión sobre la naturaleza del poder político (Capítulo I). El autor señala: “[...] la necesaria existencia de la potestad política es consiguiente a la existencia de la comunidad política. Porque hay fin político hay comunidad política; y porque hay comunidad política hay autoridad política (suprema en su orden), que posee por derecho propio la jurisdictio sobre la comunidad. He allí la formulación de la secuencia ontológica del orden político-jurídico. La autoridad no es la única causa ni la esencia de la comunidad, sino una de las causas que concurren a la existencia de la comunidad y se trata, por lo demás, de una causa subordinada al bien común, que constituye la causa final y fundamental del orden político" (Castaño, 2018, p. 10 -salvo indicación en contrario, todas las citas corresponden a Castaño, 2018-). 
Lo manifestado por Castaño se inscribe en la tradición aristotélica. Al respecto, podemos citar a Aristóteles, que en el primer párrafo de la Política dice: "Toda Polis (Estado) es, evidentemente, una comunidad, y toda comunidad no se forma sino en vista de algún bien, puesto que los hombres, cualesquiera que sean, nunca hacen nada sino en vista de lo que les parece ser bueno. Es claro, por tanto, que todas las comunidades tienden a un bien de cierta especie, y que el más importante de todos los bienes debe ser el objeto de la más importante de las comunidades, de aquella que encierra todas las demás, y a la cual se llama precisamente Polis (Estado) y comunidad política" (Aristóteles, Política, I).

En el mismo sentido, Tomás de Aquino señala: "Es propio al hombre el ser animal social y político, que vive entre la muchedumbre, más que todos los animales, los cuales declaran las necesidades que naturalmente tienen. Porque a ellos la naturaleza les preparó el mantenimiento, el vestido de sus pelos, la defensa de los dientes, cuernos y uñas, o a lo menos la velocidad para huir, y el hombre, empero, no recibió de la naturaleza ninguna de estas cosas, mas en su lugar le fue dada la razón, para que mediante ella, con el trabajo de sus manos, lo pudiese buscar todo; a lo cual un hombre solo no basta, porque de por sí no puede pasar la vida suficientemente; y así, decimos, le es natural vivir en compañía de muchos [...] Pues siendo natural al hombre el vivir en compañía de muchos, necesario es que haya entre ellos quien rija esta muchedumbre; porque donde hubiese muchos, si cada uno procurase para sí solo lo que le estuviese bien, la muchedumbre se desuniría en diferentes partes, si no hubiese alguno que tratase de lo que pertenece al bien común" (Tomás de Aquino, Tratado del gobierno de los príncipes, Libro Primero, Capítulo I).

Conforme a lo señalado, la comunidad política no es un mero ente de razón o una ficción compuesta por la suma de los individuos como los únicos seres realmente existentes, como refiere la visión liberal tal como señala el autor (p. 5), sino que se trata de un ente real, pero con realidad accidental en la categoría de relación fundada en la naturaleza social o política del hombre que sería la sustancia en la cual inhiere, que tiene como fin el bien común. No es un mero accidente contingente que puede existir o no, sino que se trata de un accidente propio (una propiedad) fundado en dicha naturaleza del hombre.

En consecuencia, la autoridad o potestad como una de las causas constitutivas de la comunidad, también es un accidente propio en la categoría de relación, pues "en la praxis concreta la acción de quien ejerce el imperio implicará necesariamente una acción correlativa de obediencia por parte de quienes reconocen su título" (p. 13).

Por eso, según el autor, en conformidad con Tomás de Aquino: 1) el poder político "es una función que consiste per se primo en la dirección de las 
conductas al bien común social y secundariamente (per se secundo) también es de su competencia la organización y el ejercicio de la coacción física para la preservación de los bienes comunitarios" (p. 15); 2) "El acto de mando, en quien ejerce el mando, entra en la categoría de acción. Su objeto terminativo es el precepto, el cual, por su parte, posee dos modos de existencia: en sí mismo y en su participación en el espíritu del subordinado. De allí que sea lícito decir que el acto de mando se consuma en la moción de la conducta del subordinado, producida por la obligación que genera el anoticiamiento imperativo de que ostenta un título de mando") (p. 15); 3) “El mando funda una clase de relaciones mixtas con una especificidad propia. Esto es: el precepto, respecto de la conducta normada, no se halla en idéntica situación a la del objeto cognoscible respecto del cognoscente. Por un lado, el precepto, esencialmente, implica una necesaria participación en la razón y en la voluntad del subordinado [...] Por otro lado, el fin del imperante es mover las conductas, medir la praxis [...] Por último, el precepto resulta de conocimiento obligatorio para el subordinado" (p. 16); 4) "La relación en que consiste el mando tiene como fundamento los predicamentos acción y pasión” (p. 16); "El Aquinate afirma que el imperio y acto imperado son simpliciter uno, pero secundum quid múltiples" (p. 16).

En conclusión, sobre esta primera parte, el autor dice: "Se puede afirmar que presupuesta la existencia de la comunidad política, la autoridad política constituye una función necesaria e inderogable ejercida por los titulares particulares en la determinación de cuyos títulos de mando concurre el consenso de quienes obedecen, y de naturaleza bipolar, la cual consiste en la dirección racional -dotada de facultades coactivas- hacia el bien común político. Se trata de una facultad directiva -cuyo modo propio de imperio es la jurisdictio- y que se halla investida de supremacía normativa sobre todo otro poder -mundano- en el ámbito de la comunidad política” (p. 38).

II. La segunda parte, referida al poder constituyente, comienza con un análisis de la naturaleza de la Constitución (Cap. II), para luego abordar específicamente el tema del poder constituyente como función del poder político (Cap. III).

La locución Constitución se relaciona con la palabra griega Politeia, entendida como estructura jurídico-política de la polis, y con la latina constitutio, que significa lo mismo según Cicerón en el De republica. Señala el autor que, según Manuel García-Pelayo, se pueden distinguir tres tipos de constitución: a) "Tipo racional-normativo. La constitución es un sistema de normas erigido de una sola vez y en el que se establecen total y exhaustivamente las funciones del Estado y las relaciones y competencias de los diversos órganos" (p. 44). En otras palabras, no es la constitución la que expresa un determinado orden, sino que dicho orden es creado por la cons- 
titución. Se trata de una concepción propia del racionalismo iluminista. b) "Tipo histórico-tradicional. La constitución de un pueblo no es un sistema producido por la razón, sino el resultado de una lenta transformación, jalonada por una multiplicidad de actos políticos atentos a circunstancias particulares y traducida por la costumbre" (p. 46). El título en que se funda es la prescripción, basando su legitimidad en que ha existido desde tiempo inmemorial. En consecuencia, la constitución no crea el orden político sino que es su expresión. Se trata de una concepción de impronta historicista y tradicional. c) "Tipo sociológico. La sociedad tiene una legalidad inmanente, irreductible a toda normatividad trascendente a ella; por último, si la concepción racional acentúa el momento de la validez, y el histórico el de la legitimidad, el sociológico lo hace con el de la vigencia" (p. 48). Para esta concepción, la estructura política de un pueblo expresada en su constitución es consecuencia de su infraestructura social. En este tipo se distingue entre constitución social (real) y constitución jurídica (formal). Se trata de una concepción sociologista.

El autor, luego de describir los tres tipos de concepciones constitucionales, señala que la más falsa y reductiva es la racional normativa, mientras que las otras dos distinguen entre constitución material (histórica tradicional o sociológica) y constitución formal (normativo-positiva).

Ahora bien, luego de señalar esto concluye: "La constitución de la comunidad política, en su dimensión más concreta (en el sentido de 'total'), consiste en un todo potestativo, compuesto de partes potenciales. Cada una de ellas participa análogamente de la noción, y realiza en cierto sentido, con mayor o menor plenitud, el papel de elemento estructurante de la comunidad. Pero sólo el todo puede llamarse ‘constitución' en sentido plenario. Se trata de la constitución como causa formal, complexiva del orden completo de las relaciones entre los miembros de la comunidad, así como de las disposiciones actitudinales que se hallan a la base de la 'normalidad' social (Heller). Es decir, se trata del orden total de la comunidad política, que abarca en una unidad superior la realidad significada por las anteriores acepciones de "constitución”' (p. 76).

III. En cuanto al poder constituyente como función del poder político (Cap. III), plantea el problema de quién es el titular y quién lo ejerce efectivamente. $\mathrm{Al}$ respecto concluye el autor: "A propósito de lo últimamente afirmado, y como cierre de este análisis filosófico-político, queremos esbozar una tesis conclusiva. Aunque se aceptaran las categorías constitucionalistas de 'poder constituyente' y 'poder constituido', solo resultaría lícito entenderlas como una dualidad de funciones en el seno del mismo poder político (correspondiente al ejercicio de las funciones constituyente y constituida), mas no como una distinción real entre dos poderes político-jurídicos. En 
efecto, según su naturaleza, el poder político es uno, más allá de la diversificación de sus órganos, funciones y objetos. Respecto de nuestro tema, esta necesidad ontológica y deóntica podría ser traducida en las propias categorías del constitucionalismo con la fórmula siguiente, con pretensión de tesis de alcance universal: el poder constituyente originario (referido, en sentido propio, al establecimiento de la constitución jurídica) está a cargo del poder constituido (entendiendo por 'poder constituido' el poder ejercido y efectivamente vigente en la comunidad). Y esta afirmación, a fortiori, vale para el poder constituyente reformador" (p. 81).

Conforme señala el autor, el poder político es uno y si bien en Dogmática constitucional se divide en constituyente y constituido, el primero es el que establece la constitución, mientras que el segundo es el que efectivamente se ejerce y, por tanto, el verdadero titular del poder político. De esta manera, rechaza el mito de la soberanía del pueblo como titular del poder constituyente, según lo va a analizar en el primero de los apéndices, a propósito de un texto de Germán Bidart Campos.

IV. Finalmente, en los apéndices trata, primero, sobre el mito de la soberanía del pueblo. Señala entonces que no se puede confundir la determinación de los títulos de quienes gobiernan con el efectivo gobierno del Estado, por lo que la expresión "soberanía del pueblo" o "de la Nación" sería abusiva e impropia. En el segundo apéndice se refiere a la objeción contrarrevolucionaria a la realidad del poder constituyente (Joseph de Maistre), en la cual, según Castaño, se estaría realizando el tránsito indebido de una opción política práctica particular (conforme a circunstancias históricas determinadas) al plano teórico de los principios, abordando -y cuestionandoel poder constituyente a partir de un postulado erróneo.

V. A modo de conclusión: la presente obra es un importante trabajo que aborda el tópico del poder constituyente desde una perspectiva filosófica política y jurídica clásica de raíz aristotélica, sin perjuicio de abordar simultáneamente los temas centrales del Derecho Constitucional. Por tal motivo, recomendamos fervientemente la lectura de Il potere costituente tra mito e realtà, primera obra del ámbito hispanoparlante traducida y publicada en la que, tal vez, sea la más prestigiosa colección italiana de teoría del Derecho y del Estado. 